\title{
EFICIÊNCIA DA SELEÇÃo RECORRENTE PARA REDUÇÃO DA ESTATURA DE PLANTÁS EM MAMONEIRA (Ricinus communis L.)
}

\author{
Recurrent selection efficiency for stature reduction of castor bean \\ (Ricinus communis L.) plants
}

\author{
Inocencio Junior de Oliveira ${ }^{1}$, Maurício Dutra Zanotto ${ }^{2}$
}

\begin{abstract}
RESUMO
Realizou-se, o presente trabalho, com o objetivo de avaliar a eficiência da seleção recorrente para a redução da estatura de plantas de mamona da cultivar Guarani (Ricinus communis L.), tornando-a com porte adequado para facilitar a colheita manual e/ou mecânica. Foram realizados quatro ciclos de seleção recorrente com a utilização de progênies autofecundadas na cultivar Guarani para redução da estatura das plantas, nas condições edafoclimáticas dos municípios de São Manuel - SP, Botucatu - SP e Penápolis - SP. As avaliações de estatura das plantas e de produtividade de grãos $\left(\mathrm{kg}_{\text {.ha }} \mathrm{h}^{-1}\right)$, dos quatro ciclos de seleção e do ciclo original foram realizadas nos municípios de São Manuel - SP, Botucatu - SP e Penápolis - SP na safra 2005/2006, sob um delineamento de blocos casualizados com cinco repetições e parcela útil de $30 \mathrm{~m}^{2}$. A análise de variância para as características avaliadas foi feita separadamente para cada local e conjuntamente para os três locais e, posteriormente, realizada a comparação das médias pelo teste de Tukey, a 5\%. Foram estimados, para as três localidades, por análise de regressão, os ganhos genéticos dos quatros ciclos de seleção para estatura de plantas. A partir dos resultados obtidos pôde-se concluir que a seleção recorrente foi eficiente para a redução da estatura de plantas e que a cultivar de mamona Guarani apresenta variabilidade genética para essa característica e que a produtividade não foi influenciada pela redução da estatura de plantas.
\end{abstract}

Termos para indexação: Mamona, variabilidade genética, ganho genético, produtividade, Ricinus communis.

\section{ABSTRACT}

The aim of this work was to evaluate the recurrent selection efficiency for reduction of stature of the castor bean plants of the Guarani cultivar (Ricinus communis L.), turning it with appropriate strucuture to facilitate the manual and/or mechanic harvest. Four cycles of recurrent selection were accomplished through the utilization of self-pollinated progenies in the Guarani cultivar for reduction of plants stature, in edaphclimatic conditions of São Manuel-SP, Botucatu-SP and Penápolis-SP towns. The evaluations of plants stature and yield $\left(\mathrm{kg}_{\mathrm{h}} \mathrm{ha}^{-1}\right)$ of the four selection cycles and the original cycle (cycle 0) were accomplished in São Manuel-SP, Botucatu-SP and Penápolis-SP, under a randomized block design with five repetitions and useful parcels of $30 \mathrm{~m}^{2}$. The analysis of variance for the characteristics plant stature and yield was made apart to each environment and together for the three environment and, afterwards one performed the average comparison by the Tukey test using $5 \%$ of probability. One estimated for the three environments, by the regression analysis, the genetic gains of the four selection cycles for plant stature. One concluded that the recurrent selection was efficient to the reduction of plant stature and that Guarani castor bean cultivar could create genetic variability for this characteristic and the yield was not influenced by the reduction of plants stature.

Index terms: Castor bean, genetic variability, genetic gain, productivity, Ricinus communis.

(Recebido em 28 de agosto de 2007 e aprovado em 14 de março de 2008)

\section{INTRODUÇÃO}

A mamoneira (Ricinus communis L.) é uma oleaginosa de alto valor social e econômico é fonte de divisas para o país. Cultura produzida tradicionalmente em pequenas e médias propriedades tem importante valor social como geradora de renda e empregos no campo. Na área industrial são inúmeras as possibilidades de aplicações e também de utilização como potencial energético (TURATTI et al., 2002).
O rendimento médio da mamona em bagas, no Brasil, na safra 2006/2007 foi de $728 \mathrm{~kg} \cdot \mathrm{ha}^{-1}$ (CONAB, 2007). A perda de competitividade é explicada pelo baixo nível tecnológico do produtor, uso incorreto de insumos e principalmente pela falta de cultivares melhoradas, adaptadas para colheita manual e/ou mecânica e para resistência às doenças, o que encarece o custo de produção (SAVY FILHO et al., 1999).

Com a ampliação da utilização do óleo de mamona extraído de suas sementes a produção da matéria-prima

\footnotetext{
'Agrônomo, Doutorando em Genética e Melhoramento de Plantas - Departamento em Genética/LGN - Escola Superior de Agricultura "Luiz de Queiroz"' ESALQ - Universidade de São Paulo/USP - Avenida Pádua Dias, 11 - Cx. P. 83 - 13400-970 - Piracicaba, SP - ijdolive@esalq.usp.br

${ }^{2}$ Agrônomo, Doutor em Genética e Melhoramento de Plantas, Professor - Departamento de Agricultura e Melhoramento Vegetal - Faculdade de Ciências Agronômicas/FCA - Universidade Estadual Paulista/UNESP - Rua José Barbosa de Barros, 1780 Fazenda Lageado - Cx. P. 237 - 18603-970 Botucatu, SP _ zanotto@fca.unesp.br
} 
precisa aumentar, visto que a produção de grãos no estado de São Paulo está muito aquém da necessidade industrial instalada. Para atender à necessidade crescente de matériaprima e dificuldade de produção em escala industrial é imprescindível o desenvolvimento de materiais genéticos de porte adequado para facilitar a colheita, com maturação precoce e uniforme, visando a utilização de alta tecnologia que possibilitem a produção da oleaginosa em maior escala.

Uma das cultivares de mamona mais plantada no estado de São Paulo é a cultivar Guarani. Ela foi obtida de produtores, teve origem na cultivar IAC Guarani lançada em 1974. As multiplicações da população, por parte dos produtores, sem utilização de técnicas de melhoramento e produção de sementes, bem como sem os devidos cuidados para evitar cruzamentos com outras cultivares e com mamoneira comum, favoreceram o surgimento de variabilidade genética para características agronômicas importantes, como por exemplo, para estatura de plantas.

Embora seja considerada uma espécie autógama (TÁVORA, 1982), a mamoneira, em função do seu sistema reprodutivo, apresenta taxa de alogamia em torno de $38 \%$ (OLIVEIRA et al., 2007), e também facilidade na obtenção de cruzamentos e autofecundações controlados.

A seleção recorrente tem sido mais extensivamente utilizada em plantas alógamas, contudo o seu emprego tem sido ampliado nas últimas décadas com sucesso, em inúmeros países, em várias espécies autógamas, como soja (UPHOFT et al., 1997), trigo (WANG et al., 1996), arroz (RANGEL et al., 1998), aveia (KOEYER et al., 1993), feijão (RANALLI, 1996).

Existem poucos trabalhos na literatura sobre herança da característica estatura de plantas na mamona. Segundo Marinkovic \& Skoric (1995), na herança da estatura de plantas o componente aditivo da variação é mais importante do que o componente dominante, indicando condição favorável para adoção da seleção recorrente. Amaral (2003) estimou parâmetros genéticos de estatura de plantas, para a população de mamona Guarani e obteve coeficiente de herdabilidade de 0,60 , indicando a possibilidade de sucesso de seleção de progênies para menor porte.

A seleção recorrente permite o acúmulo gradual de alelos favoráveis para caracteres quantitativos, como estatura de plantas e produtividade de grãos. A mamoneira é uma espécie que apresenta facilidade para a obtenção de cruzamentos artificiais com produção de grande número de sementes, sendo, portanto exeqüíveis os procedimentos de recombinação para a condução da seleção recorrente, como tem sido feito por Zanotto et al. (2004). Assim, objetivou-se, neste trabalho, avaliar a eficiência da seleção recorrente para diminuir a estatura de plantas de mamona da cultivar Guarani, visando obter uma população de plantas com porte adequado para facilitar a colheita manual e/ou mecânica.

\section{MATERIAL E MÉTODOS}

O material utilizado no presente trabalho constou da cultivar de mamona Guarani, aqui denominado ciclo original (ciclo 0) e quatro ciclos de seleção recorrente, aplicados na referida população, com a utilização de progênies autofecundadas para diminuição da estatura de plantas, denominados ciclos 1, 2, 3 e 4 .

\section{Ciclos de seleção}

Os ciclos de seleção foram obtidos em duas etapas. $\mathrm{Na}$ primeira etapa foram selecionadas e autofecundadas plantas baixas da cultivar Guarani. Em seguida, as progênies derivadas da autofecundação das plantas selecionadas foram conduzidas em lotes isolados e os racemos primários de cinco plantas de cada uma das 30 progênies mais baixas selecionadas foram protegidos por sacos de papel, conforme metodologia descrita por Savy Filho (1999).

Foram realizadas pelo menos cinco polinizações por racemo, com mistura de pólen de todas as 30 progênies selecionadas. As sementes obtidas por esse método de recombinação foram colhidas e misturadas dando origem ao ciclo de seleção, denominado ciclo 1. Esse procedimento foi repetido até a obtenção de quatro ciclos de seleção.

Os ciclos de seleção, com as respectivas fases de recombinação foram desenvolvidos no município de São Manuel, estado de São Paulo, entre os anos 2001 a 2005.

O material obtido de cada um dos ciclos de seleção foi multiplicado para avaliações posteriores.

\section{Avaliação dos ciclos de seleção}

As avaliações dos cinco ciclos de seleção para diminuição de estatura de plantas e de produtividade de grãos $\left(\mathrm{kg} \cdot \mathrm{ha}^{-1}\right)$ foram realizadas durante o ano agrícola de 2005/2006, nas cidades de Botucatu, São Manuel e Penápolis, estado de São Paulo.

Para realizar a avaliação da estatura média das plantas foram tomados dados de estatura de todas as plantas na área útil da parcela, em centímetros, desde a superfície do solo até o ápice do ramo mais alto.

$\mathrm{Na}$ avaliação de produtividade de grãos foram tomados dados da massa dos grãos dos frutos descascados em $\mathrm{kg}$, por parcela de $30 \mathrm{~m}^{2}$, corrigidos para teor de água de $10 \%$.

O delineamento utilizado foi o de blocos casualizados com cinco repetições e parcela útil de $30 \mathrm{~m}^{2}$, com espaçamento de $1 \mathrm{~m} \times 1 \mathrm{~m}$. 


\section{Análise de variância e estimativa do ganho genético}

A análise de variância para a característica estatura de plantas e produtividade de grãos foi feita separadamente para cada local e conjuntamente para os três locais, e posteriormente submetido à comparação das médias através do teste de Tukey, a 5\% de probabilidade.

Foram estimados, separadamente para cada local e conjuntamente para as três localidades, por análise de regressão, os ganhos genéticos de seleção para cada local.

\section{RESULTADOS E DISCUSSÃO}

Devido à ocorrência de homogeneidade entre os quadrados médios dos resíduos para cada local, foi realizada a análise conjunta para os três locais para a característica estatura de plantas e para produtividade de grãos.

Os quadrados médios, respectivas significâncias pelo teste $\mathrm{F}$ e coeficientes de variação experimental da análise conjunta, nos três locais, nos ciclos de seleção da cultivar Guarani, para a característica estatura de plantas (cm) e produtividade de grãos $\left(\mathrm{kg} \cdot \mathrm{ha}^{-1}\right)$, em Botucatu - SP, São Manuel - SP e Penápolis - SP observam-se na Tabela 1.

Os ciclos de seleção não apresentaram comportamento diferencial em relação aos locais para a característica estatura de plantas. Entretanto, foram observados os efeitos entre locais, assim como obteve Amaral (2003) e entre ciclos de seleção (Tabela 1).

O quadrado médio da interação de ciclos de seleção por locais, para a característica produtividade de grãos, avaliados na análise conjunta não foi significativo a $5 \%$ de probabilidade pelo teste $\mathrm{F}$ (Tabela 1). Os ciclos de seleção não apresentaram comportamento diferencial em relação aos locais para a característica produtividade de grãos.
A produtividade de grãos não foi influenciada pelo uso da seleção recorrente para reduzir a estatura de plantas.

Na Tabela 2, são apresentados os valores médios dos ciclos de seleção da cultivar Guarani para as características estatura de plantas $(\mathrm{cm})$ e produtividade de grãos (kg.ha ${ }^{-1}$ ) nos três locais, na safra 2005/2006.

A média de estatura de plantas no ciclo original (ciclo 0) foi de $310,9 \mathrm{~cm}$ e no último ciclo de seleção recorrente foi de $246,9 \mathrm{~cm}$, mostrando uma redução na estatura das plantas com o desenvolvimento dos ciclos de seleção, confirmando a existência de variabilidade genética para estatura de plantas na cultivar Guarani, como sugerido por Amaral (2003) ao estimar o coeficiente de herdabilidade de 0,60 e verificar variabilidade genética para essa cultivar, e a eficiência da seleção recorrente para redução do caráter, corroborando com os dados obtidos por Zanotto et al. (2004), na cultura da mamona. Nota-se que, já no primeiro ciclo de seleção (ciclo 1), obteve-se efeito da seleção recorrente na redução da estatura de plantas, ocorrendo redução no tamanho da planta de 29,3 cm.

Os ciclos de seleção 2 e 3, e 3 e 4, não diferiram significativamente ao nível de $5 \%$ de probabilidade pelo teste de Tukey. Mesmo assim, observa-se um ganho genético significativo se comparado com o ciclo original e o primeiro ciclo de seleção.

A média de produtividade de grãos na população original (ciclo 0) foi de $2345,7 \mathrm{~kg}$.ha- ${ }^{-1}$ e no último ciclo de seleção recorrente foi de $2365,7 \mathrm{~kg}$ ha $^{-1}$, considerada alta de acordo com Nóbrega et al. (2001), foram semelhantes a $5 \%$ de probabilidade pelo teste de Tukey, mesmo com uma redução na estatura das plantas, com o desenvolvimento

Tabela 1-Quadrados médios, respectivas significâncias pelo teste F e coeficientes de variação experimental da análise conjunta, nos ciclos de seleção da cultivar Guarani para a característica estatura de plantas (cm) e produtividade de grãos (kg.ha-1), em Botucatu - SP, São Manuel - SP e Penápolis - SP, na safra 2005/2006.

\begin{tabular}{lccc}
\hline \multirow{2}{*}{ Fontes de Variação } & G.L. & \multicolumn{2}{c}{ Quadrados Médios } \\
\cline { 3 - 4 } & 12 & $\begin{array}{c}\text { Estatura de Plantas } \\
(\mathrm{cm})\end{array}$ & $\begin{array}{c}\text { Produtividade de grãos } \\
\left(\mathrm{kg} \cdot \mathrm{ha}^{-1}\right)\end{array}$ \\
\hline Blocos & 2 & - & - \\
Locais (L) & 4 & $825,16^{*}$ & $416581,10^{\mathrm{ns}}$ \\
Ciclos de Seleção (CS) & 8 & $10218,05^{*}$ & $72938,91^{\mathrm{ns}}$ \\
CS x L & 48 & $249,73^{\mathrm{ns}}$ & $39135,92^{\mathrm{ns}}$ \\
Resíduo Médio & & 211,78 & 188523 \\
\hline CV $(\%)$ & 5,30 & 18,70 \\
\hline
\end{tabular}

*significativo a $5 \%$ de probabilidade, pelo teste $\mathrm{F}$.

ns - não significativo a $5 \%$ de probabilidade, pelo teste $\mathrm{F}$. 
Tabela 2 - Médias dos ciclos de seleção da cultivar Guarani para a característica estatura de plantas (cm) e produtividade de grãos (kg.ha-1), nos municípios de Botucatu - SP, São Manuel - SP e Penápolis - SP, na safra 2005/2006.

\begin{tabular}{ccc}
\hline \multirow{2}{*}{ Ciclos de Seleção } & Três Locais & Três Locais \\
\cline { 2 - 3 } & Estatura $(\mathrm{cm})$ & Produtividade $\left(\mathrm{kg}_{\mathrm{h}} \mathrm{ha}^{-1}\right)$ \\
\hline 0 & $310,9 \mathrm{~d}$ & $2345,7 \mathrm{a}$ \\
1 & $281,6 \mathrm{c}$ & $2219,7 \mathrm{a}$ \\
3 & $262,1 \mathrm{~b}$ & $2392,0 \mathrm{a}$ \\
4 & $252,1 \mathrm{ab}$ & $2281,9 \mathrm{a}$ \\
Média geral & $246,9 \mathrm{a}$ & $2365,7 \mathrm{a}$ \\
\hline
\end{tabular}

Letras iguais não diferem entre si pelo Teste de Tukey, ao nível de 5\% de probabilidade.

dos ciclos de seleção recorrente na população Guarani Comum. Amaral (2003), de acordo com os parâmetros genéticos estudados na mesma população utilizada no presente trabalho verificou a possibilidade de utilização de materiais produtivos e de porte menor, com possibilidade de facilidade na colheita e Jesus (2005) mostrou ser possível desenvolver linhagens de mamona baixas e com alto potencial produtivo oriundas dessa população.

Na Tabela 3, são apresentados os valores médios de estatura de plantas $(\mathrm{cm})$ da cultivar Guarani, nos três locais na safra 2005/2006.

Tabela 3 - Médias de estatura de plantas (cm) da cultivar Guarani, nos três locais na safra 2005/2006.

\begin{tabular}{lc}
\multicolumn{1}{c}{ Locais } & Altura de Plantas $(\mathrm{cm})$ \\
\hline Botucatu - SP & $276,6 \mathrm{~b}$ \\
São Manuel - SP & $270,4 \mathrm{ab}$ \\
Penápolis - SP & $265,1 \mathrm{a}$ \\
\hline DMS & 9,78
\end{tabular}

Letras diferentes diferem entre si pelo Teste de Tukey ao nível de $5 \%$ de probabilidade.

A média da estatura de plantas em Botucatu - SP foi de 276,6 cm, semelhante a de São Manuel - SP de 270,4 $\mathrm{cm}$ e diferindo de Penápolis - SP com média de $265,1 \mathrm{~cm}$. Sendo que São Manuel não diferiu de Penápolis.

Na Figura 1, indica-se o comportamento da característica estatura de plantas em função de ciclos de seleção recorrente, conjuntamente em Botucatu - SP, São Manuel - SP e em Penápolis - SP, do ciclo original até o $4^{\circ}$ ciclo de seleção da cultivar Guarani de mamona e o modelo quadrático da regressão foi o que melhor se ajustou à diminuição da estatura das plantas, em função dos ciclos de seleção, com $\mathrm{R}^{2}=0,99$.

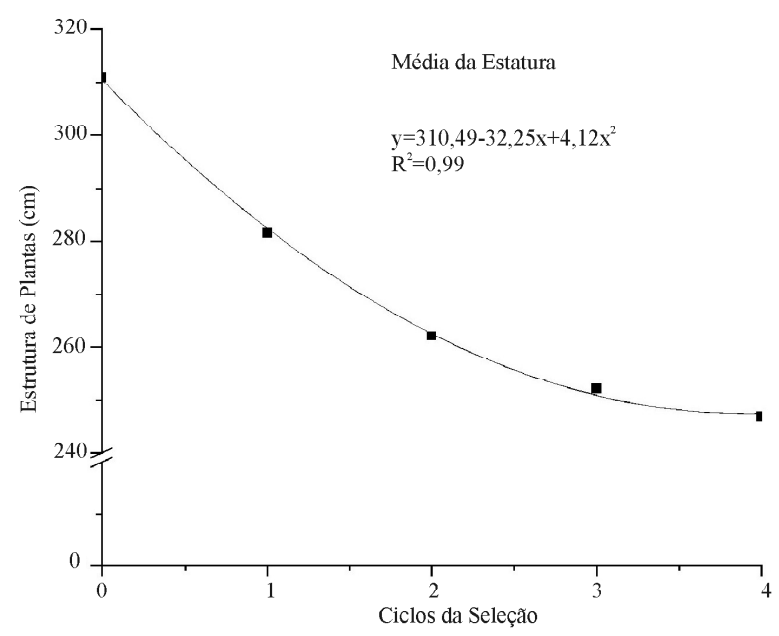

Figura 1 - Curva de regressão (modelo quadrático) da estatura de plantas de mamona, em função de ciclos de seleção em Botucatu - SP, São Manuel - SP e em Penápolis - SP, na safra 2005/2006.

A partir da equação ajustada $y=310,49-32,25 x+$ $4,12 \mathrm{x}^{2}$, obteve-se a estimativa do ganho genético por ciclo de seleção, mostrado na Tabela 4, cujo ganho total, considerando os três locais, foi de $63,08 \mathrm{~cm}$.

O ganho genético total considerando os três locais foi de $63,08 \mathrm{~cm}$ e o ganho genético em porcentagem, no ciclo 1 , em relação à média da população original ou ciclo 0 foi de $9,05 \%$, no ciclo 2 o ganho genético foi de $6,40 \%$ em relação à média da população original, já nos ciclos 3 e 4 o ganho genético em relação ao ciclo original foi de $3,75 \%$ e $1,10 \%$, respectivamente. 
Tabela 4 - Estimativa do ganho genético, por ciclo de seleção para a característica estatura de plantas nos três locais, na safra 2005/2006 em função da equação de regressão $y=310,49-32,25 x+4,12 x^{2}$ com $R^{2}=0,99$.

\begin{tabular}{cccc}
\hline \multirow{2}{*}{$\begin{array}{c}\text { Ciclos de } \\
\text { Seleção }\end{array}$} & $\begin{array}{c}\text { Gor ciclo } \\
(\mathrm{cm})\end{array}$ & $\begin{array}{c}\text { Ganho Genético } \\
\text { (em relação a média do ciclo 0) }\end{array}$ & $\begin{array}{c}\text { \% } \\
\text { (em relação ao ganho total) }\end{array}$ \\
\hline 1 & 28,13 & 9,05 & 44,59 \\
2 & 19,89 & 6,40 & 31,53 \\
3 & 11,65 & 3,75 & 18,47 \\
4 & 3,41 & 1,10 & 5,41 \\
\hline Total & 63,08 & & \\
\hline
\end{tabular}

O ganho genético por ciclo de seleção em relação ao ganho total $(63,08 \mathrm{~cm})$ foi mais expressivo nos dois primeiros ciclos de seleção, sendo de $44,59 \%$ o ganho genético no ciclo 1 e $31,73 \%$ no ciclo 2 , em relação ao ganho total. No $3^{\circ}$ ciclo de seleção, o ganho total foi de $18,47 \%$. E, no ciclo 4 , foi de $5,41 \%$ em relação ao ganho genético total. Esses resultados concordam com Geraldi (2000) que indicaram que, nos primeiros ciclos de seleção em um programa de seleção recorrente, encontra-se uma ampla variabilidade genética entre as famílias, sendo que, à medida que se sucedem os demais ciclos de seleção e a recombinação, a possibilidade de ganho de seleção é menor.

Com o desenvolvimento dos ciclos de seleção ocorreu uma redução no ganho genético, para a característica estatura de plantas da cultivar Guarani, entretanto, o uso da seleção recorrente, para redução da estatura de plantas da cultivar Guarani, foi eficiente, independente do local de cultivo.

\section{CONCLUSÕES}

A seleção recorrente foi eficiente para a redução da estatura de plantas.

A produtividade de grãos $\left(\mathrm{kg} \cdot \mathrm{ha}^{-1}\right)$ não foi influenciada pela redução da estatura de plantas.

\section{REFERÊNCIAS BIBLIOGRÁFICAS}

AMARAL, J. G. C. Variabilidade genética para características agronômicas entre progênies autofecundadas de mamona (Ricinus communis L.) cv. AL Guarany 2002. 2003. 59 f. Tese (Doutorado em Agronomia/Agricultura) - Universidade Estadual Paulista, Botucatu, 2003.

COMPANHIA NACIONAL DO ABASTECIMENTO. Indicadores da agropecuária. 2007. Disponível em: <http:/ 1/www.conab.gov.br/conabweb/download/indicadores/ IA_MAR_2007. Acesso em: 17 abr. 2007.

GERALDI, I. O. Muestreo genético para programas de mejoramiento poblacional. In: GUIMARÃES, E. P. (Ed.). Avances en el mejoramiento poblacional en arroz. Santo Antônio de Goiás: Embrapa Arroz e Feijão, 2000. p. 9-19.

JESUS, C. R. Avaliação de linhagens da população FCA planta baixa de mamona (Ricinus communis L.). 2005. 36 f. Dissertação (Mestrado em Agronomia/Agricultura) Universidade Estadual Paulista, Botucatu, 2005.

KOEYER, D. L. de; STUTHMAN, D. D.; FULCHER, R. G.; POMERANKE, G. J. Effects of recurrent selection for grain yield on oat kernel morohology. Crop Science, Madison, v. 33, n. 5, p. 924-928, 1993.

MARINKOVIC, R.; SKORIC, D. Components of genetic variability of castor oil plant height, number of leaves and number of branches (Ricinus communis L.). In: CONFERENCE ABOUT PRODUCTION AND PROCESSING OF OIL CROPS, 36., 1995. Proceedings... [S.1.: s.n.], 1995. p. 310-314.

NÓBREGA, M. B. M. et al. Germoplasma. In: AZEVEDO, D. M. P. de; LIMA, E. F. (Eds.). O agronegócio da mamona no Brasil. Brasília, DF: Embrapa Algodão, 2001. cap. 11, p. 257-281.

OLIVEIRA, I. J.; ZANOTTO, M. D.; MYCZKOWSKI, M. L.; AMARAL, J. G. C. Taxas de cruzamentos naturais na cultivar Al Guarani de mamona (Ricinus communis L.). In: CONGRESSO BRASILEIRO DE MELHORAMENTO DE PLANTAS, 4., 2007, São Lourenço. Anais... Lavras: UFLA, 2007. CD-ROM. 
RANALLI, P. Phenotypic recurrent selection in common bean (Phaseolus vulgaris L.) based on performance of $\mathrm{S}_{2}$ progenies. Euphytica, Wageningen, v. 87, n. 2, p. 127-132, 1996.

RANGEL, P. H. N.; ZIMMERMANN, F. J. P.; NEVES, P. C. F. Estimativas de parâmetros genéticos e resposta à seleção nas populações de arroz irrigado CNA - IRAT 4 PR e CNA - IRAT 4 ME. Pesquisa Agropecuária Brasileira, Brasília, v. 33, p. 905-912, 1998.

SAVY FILHO, A. et al. Mamona. In: COORDENADORIA DE ASSISTÊNCIA TÉCNICA INTEGRAL. Oleaginosas no estado de São Paulo: análise e diagnóstico. Campinas, 1999a. 39 p. (Documento técnico, 107).

SAVY FILHO, A. Hibridação em mamona. In: BORÉM, A. (Ed.). Hibridação artificial de plantas. Viçosa: UFV, 1999b. p. 331-342.

TÁVORA, F. J. A. F. A Cultura da mamona. Fortaleza: Empresa de Pesquisa Agropecuária do Ceará, 1982. 111 p.
TURATTI, J. M.; GOMES, R. A. R.; ATHIÉ, I. Lipídeos: aspectos funcionais e novas tendências. Campinas: Instituto de Tecnologia de Alimentos, 2002. 78 p.

UPHOFT, M. D.; FEHR, W. R.; CIANZIO, S. R. Genetic gain for soybean seed yield by three recurrent selection methods. Crop Science, Madison, v. 37, n. 4, p. 1155-1158, 1997.

WANG, X. W.; LAI, J. R.; FAN, L.; ZHANG, R. B. Effects of recurrent selection on populations of various generations in wheat by using the Tai Gu single dominat male-sterile gene. Journal of Agricultural Science, Cambridge, v. 126, p. 397-402, 1996.

ZANOTTO, M. D. et al. Seleção recorrente com utilização de progênies autofecundadas para diminuição da estatura de plantas de mamona (Ricinus communis L.) população Guarani Comum. In: CONGRESSO BRASILEIRO DE MAMONA, 1., 2004, Campina Grande. Energia e sustentabilidade. Disponível em: 4http://Www. embrapa.br/produtos/mamona/publicacoes/trabalhos_ cbm1/066.PDF>. Acesso em: 31 mar. 2007. 